\title{
Preliminary data on the prevalence of psychiatric disorders in Brazilian male and female juvenile delinquents
}

R.C. Andrade ${ }^{1,2}$, V.A. Silva ${ }^{2,3}$ and F.B. Assumpção Jr. ${ }^{1}$

\author{
${ }^{1}$ Departamento de Psiquiatria, Faculdade de Medicina, \\ Universidade de São Paulo, São Paulo, SP, Brasil \\ ${ }^{2}$ Centro Regional Integrado de Atendimento ao Adolescente (CRIAA/UFF), \\ Departamento de Psiquiatria e Saúde Mental, and \\ ${ }^{3}$ Departamento de Fisiologia e Farmacologia, Universidade Federal Fluminense, \\ Niterói, RJ, Brasil
}

\section{Correspondence \\ V.A. Silva \\ Rua Hernani Pires de Mello, 101 \\ 24210-130 Niterói, RJ \\ Brasil \\ E-mail: dudaortega@uol.com.br}

Publication supported by FAPESP.

.....................

Received April 11, 2003

Accepted April 8, 2004

\begin{abstract}
The aim of the present investigation was to study the prevalence of psychiatric disorders in a sample of delinquent adolescents of both genders and to compare the prevalence between genders. A total of 116 adolescents (99 males and 17 females) aged 12 to 19 on parole in the State of Rio de Janeiro were interviewed using the screening interview based on the Schedule for Affective Disorders and Schizophrenia for School-Age Children - Present and Lifetime (KSADS-PL). Data were collected between May 2002 and January 2003. Of 373 male and 58 female adolescents present in May 2002 in the largest institution that gives assistance to adolescents on parole in the city of Rio de Janeiro, 119 subjects were assessed (three of them refused to participate). Their average age was 16.5 years with no difference between genders. The screening interview was positive for psychopathology for most of the sample, with the frequencies of the suggested more prevalent psychiatric disorders being $54 \%$ for attention-deficit/hyperactivity disorder, $77 \%$ for conduct disorder, $41 \%$ for oppositional defiant disorder, $57 \%$ for anxiety disorder $57,60 \%$ for depressive disorder $60,63 \%$ for illicit drug abuse, and $58 \%$ for regular alcohol use. Internalizing disorders (depressive disorders, anxiety disorders and phobias) were more prevalent in the female subsample. There was no significant difference in the prevalence of illicit drug abuse between genders. There were more male than female adolescents on parole and failure to comply with the sentence was significantly more frequent in females. The high prevalence of psychopathology suggested by this study indicates the need for psychiatric treatment as part of the prevention of juvenile delinquency or as part of the sentence. However, treatment had never been available for $93 \%$ of the sample in this study.
\end{abstract}

Key words

- Delinquency

- Conduct disorder

- Psychiatry disorders

- Adolescents

- Parolees

- Illicit drug use 
The growth of violence in Brazil is no longer a question of statistics but a part of its population's daily life. Government statistics show that an increasing number of adolescents are committing acts of violence (1). People are afraid of children who, instead of playing with toy guns, use real ones to threaten them. However, this is not a specific Brazilian problem but one affecting other countries, even developed ones (2). For this reason many scientific studies are being published that address this phenomenon, seeking to understand it and to find possible strategies by which it might be reduced (3). Although there is extensive research on juvenile delinquency, the studies focus on males and there is little information about delinquent girls (3-5).

The aim of the present investigation was to study the prevalence of psychiatric disorders in a sample of delinquent adolescents of both genders who were on parole in the State of Rio de Janeiro. As far as we know, no studies carried out in Brazil on this subject have been published (MEDLINE, 1966 to April 2003). The available literature is based on international studies in countries with very different cultures and more favorable social and economic conditions, variables that must be considered when assessing the diagnoses of mental disorders (6).

The present study was approved by the Ethics Committee for Research Project Analysis of the Clinical Board of Hospital das Clínicas and the São Paulo University Medical School.

The sample consisted of 116 young offenders ( 99 males and 17 females) aged 12 to 19. All of them were on parole, serving sentences in a government institution named "Pólo de Liberdade Assistida da Ilha do Governador" reserved for offenders who receive this kind of sentence. Data were collected between May 2002 and January 2003. Inclusion criteria were: adolescents of both genders aged 12 to 19 , serving a sentence on parole in the State of Rio de Janeiro, with informed consent from the offender and his/her guardian to participate in the study. Subjects were excluded from the study when they and/or their guardians refused to participate or when they were serving a sentence but were not on parole.

Subjects were interviewed using the Schedule for Affective Disorders and Schizophrenia for School-Age Children - Present and Lifetime (K-SADS-PL) (7) consisting of a semi-structured interview subdivided into three main parts aiming to provide full life and current diagnoses. The first part of the interview consisted of identification, demographics, general health history and present health care, development, past history of abuse, psychiatric history, school background, and social relations. The second part consisted of an 82-symptom screen to rate key symptoms for current and past episodes in 20 different diagnostic areas. The third part consisted of 5 supplementary diagnostic score sheets (i.e., affective, psychotic, anxiety, behavioral, and substance abuse/other disorders) containing confirmatory diagnostic symptom ratings where screening was positive. No supplementary interview was required if a patient scored positive for posttraumatic stress disorder, social phobia, encopresis, and enuresis. In these cases, supplementary questions are included in the screening questionnaire. The screening interview also provides information on initition to, and abuse of, alcohol and other drugs. The screening interview was described as effective in providing a diagnostic overview of lifetime psychopathology, was effective in differentiating a psychiatric sample from normal subjects and compares favorably with other instruments (8). The supplementary diagnostic sheets (the third part of the instrument) were not applied because volunteers perceived the interview as too long and were not willing to spend more time in an additional evaluation. All interviews were carried held by a single researcher (R.C. Andrade) to avoid methodological bias. 
Research was planned around the Institution's routine in order to disturb it as little as possible. The adolescents were therefore selected on the day they received assistance. Assistance is provided for each adolescent on specific days. Any professional on the assistance team may require an adolescent to be present. On the day specified for legal assistance subjects and their respective guardians were invited by the researcher to take part in the study and were informed that their participation in the research was voluntary and confidential and that at any time they could withdraw without being penalized. On agreeing to take part, they signed a written consent. The adolescents were interviewed first, followed by their guardians, according to the protocol. Each parent and child interview took approximately $40 \mathrm{~min}$ each.

Parametric and nonparametric tests were used as needed. Proportions were compared using the chi-square test. The significance level was set at 0.05 .

In May 2002 there were 431 adolescents being assisted at the institution. These adolescents were called once or twice per month for legal assistance. Between May 2002 and January 2003, the researcher collected data three times a week. On these specific days she invited all the adolescents who attended the institution and were with a guardian to take part in the study. This procedure resulted in a selected sample of 119 adolescents. One hundred and sixteen adolescents agreed to participate and three refused (all males); those who did not agree were not invited again. Of the total number of offenders, 373 were males and 48 were females. This discrepancy between the number of males and females in the penal system has been reported in many studies $(2,4,9)$ and has many possible explanations $(4,10)$. One of them is that conduct disorder is more prevalent in boys than in girls at a ratio of 5:1 to 3.2:1 (4). Moreover, there are also genderspecific features, with a tendency towards aggression among boys, and a tendency towards covert crimes and prostitution among girls. These differences cause boys to be more easily arrested than girls. In addition to the smaller number of females in custody, statistics show that females comply less frequently with their sentences than males: of the total sample ( 373 males and $58 \mathrm{fe}$ males), 107 males and 25 females were not attending the appointment ordered by the court ( $\mathrm{P}=0.0391$, chi-square test) (11). Taken together, these two characteristics resulted in only a small number of girls available for the study.

The average age of the sample was 16.3 years $( \pm 1.3)$, with no difference between genders. There was no ethnic predominance. About $45 \%$ of the adolescents were attending school and only $23.3 \%$ lived with both parents.

As for perinatal and pregnancy history, $14 \%$ of the subjects reported some perinatal distress, $24.6 \%$ were exposed to alcohol intra-uterus, $1.7 \%$ to illicit drugs intra-uterus, and $33.3 \%$ to tobacco intra-uterus.

Only $17.2 \%$ subjects reported physical abuse during childhood and no sexual abuse was reported. These data are probably understated because information of this kind is usually not disclosed to an interviewer in a single session.

Regarding psychiatric history, 37\% of the subjects reported psychiatric pathology within the family, $5.3 \%$ of the subjects had received psychiatric treatment in the past but none were under treatment during the study period, and $17.5 \%$ had used psychotropic medication - mainly benzodiazepines prescribed while in prison.

The prevalence of alcoholism within the family was $75 \%$, a much higher level than the normal level for the Brazilian adult population, which is $10 \%$ (12). Illicit drug use in the family was also high: $45 \%$.

The most common offences committed by the sample were armed assault (28.7\%), drug dealing (23.5\%) and theft (17.4\%). The rate of recidivism in males was significantly 
higher than in females.

The screening interview indicated that psychopathology was present in most of the adolescents. The most prevalent psychiatric disorders in the sample were attention-deficit/hyperactivity disorder (54\%), conduct disorder (77\%), oppositional defiant disor-

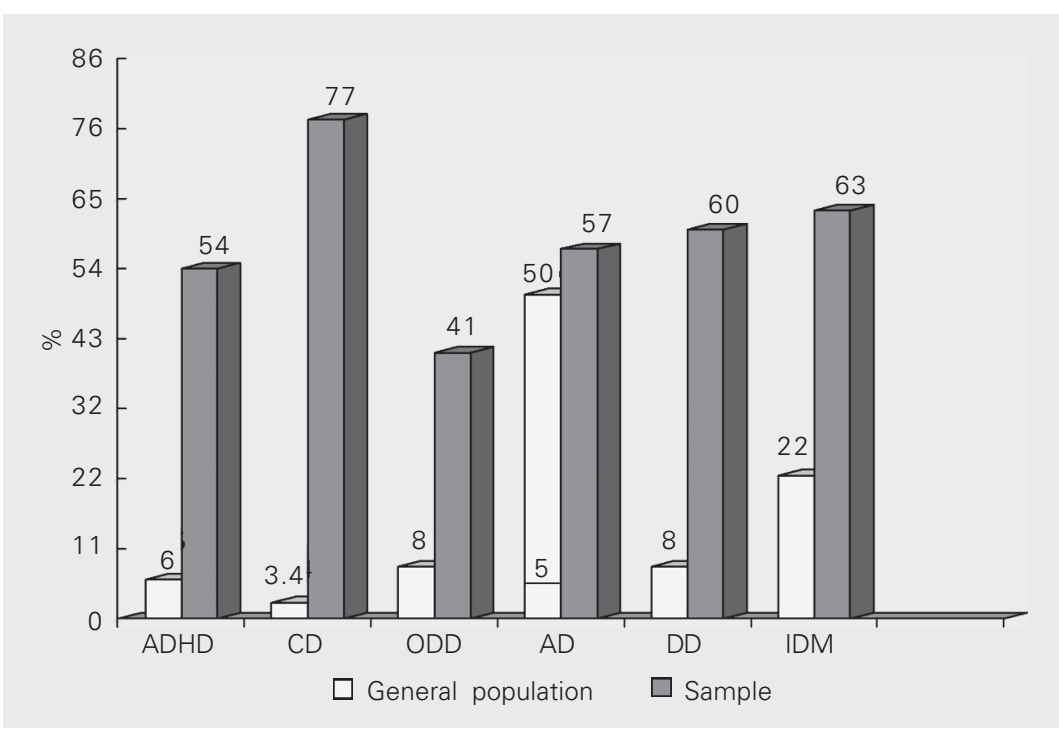

Figure 1. Prevalence of psychiatric disorders in the sample of 116 adolescent parolees of both genders compared to the prevalence found in several studies of the general population. $A D H D=$ attention-deficit/hyperactivity disorder (14); $C D=$ conduct disorder (4); $\mathrm{ODD}=$ oppositional defiant disorder (15); $\mathrm{AD}=$ anxiety disorder (16); $\mathrm{DD}=$ depressive disorder (17); IDM = illicit drug misuse (13). The exact percentages of frequency are shown by the numbers at the top of the columns.

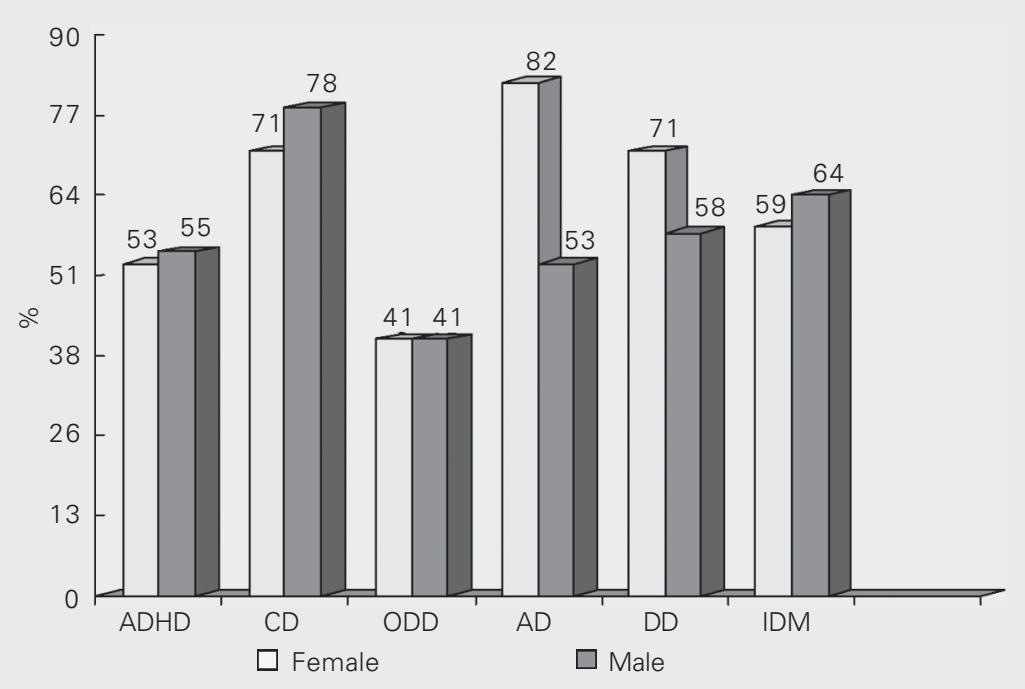

Figure 2. Prevalence of psychiatric disorders in the male subsample $(N=99)$ compared to the female subsample $(N=17)$. For abbreviations, see legend to Figure 1 . The exact percentages of frequency are shown by the numbers at the top of the columns. der $(41 \%)$, anxiety disorder (57\%), depressive disorder $(60 \%)$, and illicit drug abuse (63\%). Marihuana was the most prevalent illicit drug reported (43\%). The prevalence of regular alcohol use was 58\%. Although alcohol use is not a psychiatric disorder it is associated with disruptive behavior in adolescence (13). These statistics agree with the literature, which suggests that these diagnoses are more common in the delinquent population. A comparison between the prevalence in the sample and the prevalence found in several studies $(4,13-17)$ of the general population of adolescents is shown in Figure 1. It should be remembered, however, that these results may be overestimated since they were collected by using only the screening interview of K-SADS-PL. However, the prevalence of psychopathology in this sample can be considered high since only $4.3 \%$ of the sample did not screen positive for any mental disorder.

Besides, the reliability and validity study (7) found that psychiatric outpatients screened positive for an average of 3.7 current diagnoses. In the present study the average was 4.4. Therefore, we may conclude that Brazilian delinquent adolescents screened positive just as American psychiatric outpatients of the same age group. In the validation study, a positive screening for current disorder was found in less than $10 \%$ of the control population. In the present study it was possible to exclude the following mental disorders, which never screened positive in the sample: mania, encopresis, anorexia, and bulimia. Among the diagnoses that could be reached by the screening interview, post-traumatic stress disorder was found in $7.8 \%$, enuresis in $26.7 \%$, and social phobia in $10.3 \%$ of the sample. There was no significant difference between genders in the prevalence of disruptive disorders: attention-deficit/hyperactivity disorder (55\% among males and 53\% among females; $\mathrm{P}=0.9$, chi-square test), oppositional defiant disorder $(41 \%$ in both genders), and conduct disorder (78\% among 
males and $71 \%$ among females; $\mathrm{P}=0.70$, chi-square test). This similarity between genders was unexpected since these pathologies are more prevalent among males (4). A possible explanation is the fact that we were studying delinquent females who had been arrested and not females from the general population. There are studies suggesting that in more severely disturbed girls the genderspecific symptoms disappear (4). Apparently we had a sample of more disturbed girls that might exhibit a higher rate of disruptive behavior. This might explain why the girls from our sample tended not to attend the appointment ordered by the court.

Internalizing disorders were more prevalent in the female subsample: depressive disorder (54\% in males and $71 \%$ in females) and anxiety disorder $(52 \%$ in males and $82 \%$ in females). The higher prevalence of internalizing disorders in adolescent females has been suggested in other studies (13). There was no significant difference in the prevalence of illicit drug abuse between genders ( $\mathrm{P}$ $=0.70$, chi-square test; Figure 2).

Adolescents screening positive for conduct disorder started regular alcohol use significantly earlier compared to those not suffering from this disorder $(14.2 \pm 1.5 v s$ $15.1 \pm 1.3 ; \mathrm{P}=0.001$, Student $t$-test). Adolescents screening positive for conduct disorder also reported significantly more lifetime use of illicit drugs compared with those not suffering from this disorder $(\mathrm{P}<0.01)$.

In conclusion, the present study suggests that the prevalence of psychiatric disorders in adolescents who are in custody may be high. This finding was especially frequent for attention-deficit/hyperactivity disorder, conduct disorder, oppositional defiant disorder, depressive disorder, and illicit drug abuse. At least illicit drug abuse can be prevented. Knowledge of the high prevalence of these disorders in this particular group and the possible role of risk factors which may cause an increase in delinquency should guide preventive policies for the protection of children and adolescents. Although specific pharmacological treatment is available for attentiondeficit/hyperactivity disorder and depressive disorder, it had never been provided to $93 \%$ of the adolescents in our sample, either before or after arrest. Treatment of psychiatric disorders in adolescents should be more seriously considered. The number of special public units needs to be increased and they need to be provided as part of government health policies.

\section{Acknowledgments}

We would like to thank Mr. Gervase Shorter for reviewing the manuscript, the staff of Polo de Liberdade Assistida da Ilha do Governador for their kind support to the researcher during data collection, Prof. Pedro Carvalho Rodrigues and Prof. Vera Chiara for their help with the statistical analyses, and the adolescents and their mothers that patiently agreed to participate in the study.

\section{References}

1. Brazilian Justice Ministry (2001). Available at http://www.mj.gov.br.

2. Group for the Advancement of Psychiatry, Committee on Preventive Psychiatry (1999). Violent behavior in children and youth: preventive intervention from a psychiatric perspective. Journal of the American Academy of Child and Adolescent Psychiatry, 38 : 235-241.

3. Cauffman E, Feldman SS, Waterman J \& Stein H (1998). Posttraumatic stress disorder among female juvenile offenders. Journal of the American Academy of Child and Adolescent Psychiatry, 37: 1209-1216

4. Steiner H (1997). Practice parameters for the assessment and treatment of children and adolescents with conduct disorder. Journal of the American Academy of Child and Adolescent Psychiatry, 36: 122S-139S.

5. Steiner H, Cauffman E \& Duxbury E (1999). Personality traits in juvenile delinquents: relation to criminal behavior and recidivism. Journal of the American Academy of Child and Adolescent Psychiatry, 38: 256-262.

6. American Psychiatric Association (1994). Diagnostic and Statistical Manual of Mental Disorders. 4th edn. American Psychiatric Association, Washington, DC, USA.

7. Ambrosini PJ (2000). Historical development and present status of 
the schedule for affective disorders and schizophrenia for schoolage children (K-SADS). Journal of the American Academy of Child and Adolescent Psychiatry, 39: 49-58.

8. Kaufman J, Birmaher B, Brent D, Rao U, Flynn CMA, Moreci P, Williamson D \& Ryan N (1997). Schedule for affective disorders and schizophrenia for school-age children - present and lifetime version (KSADS-PL): initial reliability and validity data. Journal of the American Academy of Child and Adolescent Psychiatry, 36: 980-988.

9. Randall J, Henggeler SW, Pickrel SG \& Brondido M (1999). Psychiatric comorbidity and the 16-month trajectory of substance-abusing and substance-dependent juvenile offenders. Journal of the American Academy of Child and Adolescent Psychiatry, 38: 1118-1124.

10. Assis SG \& Constantino P (2000). Filhas do Mundo: Infração Juvenil Feminina no Rio de Janeiro (Sumário Executivo). Editora Fiocruz, Rio de Janeiro, RJ, Brazil, 16-23.

11. Rodrigues PC (2003). Bioestatística. Editora da Universidade Federal Fluminense, Niterói, RJ, Brazil.

12. Laranjeiras RC \& Pinsky | (1997). O Alcoolismo. Editora Contexto, São Paulo, SP, Brazil, 7.
13. Taylor J, Malone S, lacono W \& McGue M (2002). Development of substance dependence in two delinquency subgroups and nondelinquents from a male twin sample. Journal of the American Academy of Child and Adolescent Psychiatry, 41 (Suppl 4): 386393.

14. Rodhe LA, Busnello ED, Chachamovich E, Vieira GM, Pinzon V \& Ketzer CR (1998). Transtorno de déficit de atenção/hiperatividade: revisando conhecimentos. Revista da Associação Brasileira de Psiquiatria - Associación de Psiquiatria de la America Latina, 20 (Suppl 4): 166-178.

15. Loeber R, Burke J, Lahey BB, Winters A \& Zera M (2000). Oppositional defiant and conduct disorder: a review of the past 10 years. Part I. Journal of the American Academy of Child and Adolescent Psychiatry, 39 (Suppl 12): 1468-1484.

16. Lewis M (1995). Tratado de Psiquiatria da Infância e Adolescência. Chapter 58. Editora Artes Médicas, Porto Alegre, RS, Brazil, 687.

17. Versiani M, Reis R \& Figueira I (2000). Diagnóstico do transtorno depressivo na infância e adolescência. Jornal Brasileiro de Psiquiatria, 49: 367-382. 